\title{
Hate mail, tobacco control and social change
}

\section{Ruth E Malone}

As a result of the USA's latest mass shooting, there are calls for more civil and civilised discourse. ${ }^{1}$ The propagation of 'hate speech' towards political opponents, some say, led to this tragedy by fomenting and encouraging always unstable individuals to act on their most violent impulses. While the similarly inflammatory rhetoric of tobacco industry-supported 'smokers' rights' groups ${ }^{2}$ is familiar to most tobacco control advocates and many researchers, I can't help but wonder at some of the exceptionally vitriolic correspondence recently received at the journal, particularly since we instituted the Tobacco Control blog (see http://blogs.bmj.com/tc/).

The blogosphere, unfortunately, has emerged as a place for all manner of anonymous adolescent angst and anger to be indiscriminately disgorged and widely disseminated. I am not sure why we thought perhaps the TC blog might be different, but it most assuredly receives its full share-most of which we do not publish because it simply upchucks an undigested stew of incoherent fury and makes no real contribution to the purpose of the blog. For example, among the recent unpublished tirades was one from 'social leper', also known as SickofitAll on another blog, who wrote: "I fucking hate you and your profession. I've paid for my iron lung-and her brat's incubator, and that fat bastard's reinforced bed...You should all be lined up against a wall and shot in your motherfucking faces". The rant goes on to issue threats of violent rape in graphic detail and ends by saying "You've severely underestimated the hatred brewing...".

Much of this was inspired, apparently, by our first poll, asking people to weigh in with their best ideas for new ways to talk about tobacco control. We received a number of great ideas aimed at helping people make the shift from thinking and talking about these deadly products as normal everyday consumer items to

Correspondence to Professor Ruth E Malone, University of California, San Francisco, Department of Social and Behavioral Sciences, 3333 California Street, Suite 455, University of California, San Francisco, CA 94118, USA; ruth.malone@ucsf.edu thinking about the industrial epidemic of disease and the massive numbers of premature deaths they have caused over the past century. The best of these were assembled into an utterly non-scientific online poll and voted upon by whoever wished to do so.

The poll was won by a smoker, one James Watson, also known in online forums as J Watso or Junican, who had suggested emphasising how profits leave the countries of smokers while the health costs remain there, an idea touched upon by several thoughtful TC articles, including a recent analysis by Callard. ${ }^{3}$ To most of us working to check the advance of the tobacco epidemic globally, this seems fundamental, a guiding concept informed by basic values of social justice. However, Mr Watson apparently thought this idea 'rather over the top' and 'clearly, tongue in cheek' and reached out to readers of anti-regulatory blogs to encourage them to vote for his entry. Apparently, a number did so.

After we congratulated him on his win and awarded the prize (a free year's online subscription to the journal) he published on another blog a 'victory speech' attacking the idea he had submitted and the premise of the poll, and expressing outrage that we had identified him by name, although he himself had done so on other blogs and perhaps did not recognise these are accessible to anyone (see http://frank-davis. livejournal.com/130626.html). According to his post, he is a 71-year-old man who cares for a 69-year-old woman who is disabled, and he is angry about the pub smoking ban (suggesting that he may reside in the UK where such a ban is a relatively new development; in many other places both smokers and non-smokers have enjoyed smoke-free restaurants and bars for years).

Social change is almost always difficult, even on a relatively modest scale, as I can attest from my own experience with trying to adapt to burgeoning technological change. There is no question that those who still smoke and must now go outside to do so are inconvenienced in many ways. However, millions of people have adjusted to such policy change and found that they enjoy leaving a bar or pub not smelling like an ashtray, and not experiencing a raspy throat from breathing others' smoke. The evidence that secondhand smoke harms nonsmokers is now quite voluminous and no longer 'controversial', as tobacco companies so long sought to suggest through their now-exposed global conspiracy. ${ }^{4} 5$

But: 'there is no tobacco industry conspiracy', argued anti-regulation wouldbe blogger 'Jo'. Others opine that because they know someone who smoked and lived to be age 90, smoking is harmless. Such messages, I think, suggest that advocates around the globe still need to do a better job of educating the public about the tobacco industry's decades of deception, revealed through the company's own documents, which are now available to anyone with an internet connection. In too many countries, the tobacco issue remains primarily defined as a problem of individual health behaviour, rather than a problem of industry deception and aggressive promotion of highly engineered, addictive and deadly products. This may at least partially account for the personal level of anger these letters often reveal.

Flat-earthers will always be with us, and numerous industry-supported front groups, political websites and other organisations seek them out, preying on individuals' lack of knowledge to advance corporate political ends. ${ }^{6}$ These entities' aim, as the internal tobacco company documents have shown, is to counter government efforts to rein in corporate power, prioritising the fiscal health of multinational corporations over the physical health of ordinary citizens. Such organisations convince by cloaking their arguments in the rhetoric of 'freedom'. Finally, however, governments are beginning to see through these fake arguments and false organisations and are acting to protect public health.

One hopes that the most poisonous among the anti-tobacco control writers are merely venting their frustrations with the changing social climate and that they do not really intend to rape and murder those who disagree with them. But those who seek to advance public health and social justice always have faced opposition. Social change requires commitment, courage and, perhaps most especially, camaraderie.

The maleficent emails like those above are more than offset by messages that raise my spirits and remind me of the global community of which I am grateful to be a part, like one yesterday from an 
advocate in Idaho wanting to share a previously published editorial with her colleagues. All over the world, people are working vigilantly towards a time when this industry-facilitated slaughter will be checked. Many face daunting obstacles and vociferous, verbally aggressive opponents. Perhaps we can never win the hearts of Mr Watson and his fans, but they too need to understand who is being challenged, who is being fought for and to what end. We cannot fear to confront our opponents at any level, but we must always remember that our enemies are not people like Mr Watson and his companions, but those who have and would sacrifice their health, wealth and very lives for corporate profits.
Acknowledgment Thanks to Patricia McDaniel for comments on a draft of this editorial.

Competing interests RM owns one share each of Philip Morris/Altria, Philip Morris International and Reynolds American Tobacco Company stock for research and advocacy purposes. She served as a tobacco industry documents consultant for the US Department of Justice in USA vs Philip Morris et al.

Provenance and peer review Not commissioned; not externally peer reviewed.

Tobacco Control 2011;20:87-88.

doi:10.1136/tc.2011.043125

\section{REFERENCES}

1. Nichols H, Armstrong D. Obama calls for civility over conflict in shooting aftermath. In: Bloomberg News. http://www.bloomberg.com/news/2011-01-13/ obama-warns-against-pointing-fingers-in-memorial- after-arizona-shooting.html. 2011 (accessed 19 Jan 2011).

2. Smith EA, Malone RE. 'We will speak as the smoker': the tobacco industry's smokers' rights groups. Eur J Public Health 2007;17:306-13.

3. Callard CD. Follow the money: How the billions of dollars that flow from smokers in poor nations to companies in rich nations greatly exceed funding for global tobacco control, and what might be done about it. Tob Control 2010;19:285-90.

4. Francey N, Chapman S. "Operation Berkshire": the international tobacco companies' conspiracy. BMJ 2000;321:371-4

5. McDaniel PA, Intinarelli G, Malone RE. Tobacco industry issues management organizations: creating a global corporate network to undermine public health. Global Health 2008;4:2. http://www. globalizationandhealth.com/content/4/1/2.

6. Smith EA. 'It's interesting how few people die from smoking': tobacco industry efforts to minimize risk and discredit health promotion. Eur J Public Health 2007:17:162-70 